Proc 12 th 1PVS Congress, Vol. 2, The Hague, 1992, P. 496-512.

9. Morrow W.E., Britt J., Belschner A. Effect of injecting sows with prostaglandin F-2a immediately postpartum on suol.4, No. 2, P. 73-78.

10. Nissen A.K., Soede N.M., Hyttel P. The influence of time of insemination relative to time of ovulation on farrowing frequency and litter size in sows as investigated by ultrasonography // Theriogenology,1997, Vol. 47, P. 1571-1582.

11. Pressing A.L. Pharmacologic control of swine reproduction // Food Animal Practice, 1992, Vol. 8, P. 707-723.

12. Upreti G.C., Oliver D.M., Dyganzich D.M.Delelopment of a chemically ram semen diluent (RSD-1)//Anim. Reprod. Sci, 1995,Vol. 37, P. 143-157.

13. Vinter P., Cerovsky J.Vlivpridavkusyntetickehoa nalogu PGF-2 $\alpha$ - oestro-phanuspofa do inseminacnidavkynaprodnostprasnic // Zivocisna Vyroba, 1985, Vol. 30, No. 3, P. 245-250.
Авдеенко Владимир Семенович, $\partial-p$ вет. наук, проф. кафедры «Болезни животных и ветеринарно-санитарная экспертиза», Саратовский государственный аграрный университет имени Н.И. Вавилова. Россия.

Молчанов Алексей Вячеславович, $\partial-p c$. $-x$. наук, проф., зав. кафедрой «Технология производства и переработки продукиии животноводства», Саратовский государственный аграрный университет имени Н.И. Вавилова. Россия.

Филатова Алена Владимировна, канд. биол. наук, доиент кафедры «Болезни животных и ветеринарно-санитарная экспертиза», Саратовский государственный аграрный университет имени Н.И. Вавилова. Россия.

Кривенко Дмитрий Валентинович, $\partial-p$ вет. наук, проф. кафедры «Болезни животных и ветеринарно-санитарная экспертиза», Саратовский государственный аграрный университет имени Н.И. Вавилова. Россия.

410005, г. Саратов, ул. Соколовая, 335

Тел.: (8452) 69-25-32.

Ключевые слова: свиноматки; послеотъемный период; половой изикл; депрессия половой функиии; гормональные пре параты; биохимические методы исследования крови.

\title{
CORRECTION OF THE REPRODUCTION PROCESS IN BREEDING PIGS WITH SEXUAL DEPRESSION SYNDROME
}

Avdeenko Vladimir Semenovich, Doctor of Veterinary Sciences, Professor of the chair "Animals' Diseases and Veterinarian-sanitarian Expertise", Saratov State Agrarian University named after N.I. Vavilov. Russia.

Molchanov Alexey Vyacheslavovich, Doctor of Agricultural Sciences, Professor, Head of the chair "Technology of Production and Processing of Livestock Prod-uct", ", Saratov State Agrarian University named after N.I. Vavilov. Russia.

Philatova Alena Vladimirovna, Candidate of Biological Sciences, Associate Pro-fessor of the chair "Animals' Diseases and Veterinarian-sanitarian Expertise", Saratov State Agrarian University named after N.I. Vavilov. Russia.

Krivenko Dmitriy Valentinovich, Doctor of Veterinary Sciences, Professor of the chair "Animals' Diseases and Veterinari- an-sanitarian Expertise", Saratov State Agrarian University named after N.I. Vavilov. Russia.

Keywords: breeding pigs; post-weaning period; the sexual cycle; depression of sex-ual function; hormonal preparations; biochemical methods of blood research.

The stimulating potentialities of the preparation “MAPRELIN® XR10 Veiks" were studied. It was revealed that it increases the number of sows in heat with a syndrome of sexual depression after weaning piglets by $10.0 \%$, reduces the time of manifestation of the sexual cycle after treatment by 4.6 days in comparison with gonadotrophic preparation "PMSG®" and increases fertilization from the first in-semination by $8.1 \%$.

УдК 619:616.3-008.1:363.2

\section{УНИФИКАЦИЯ МЕТОДА ОПРЕДЕЛЕНИЯ МОЛЕКУЛ СРЕДНИХ МАСС ДЛЯ ДИАГНОСТИКИ НАРУШЕНИЙ РУБЦОВОГО ПИЩЕВАРЕНИЯ У ЖВАЧНЫХ}

\begin{abstract}
АЛЕХИН Юрий Николаевич, Всероссийский научно-исследовательский институт патологии, фармакологии и терапии Российской академии сельскохозяйственных наук
\end{abstract}

ЖУкОВ Максим Сергеевич, Всероссийский научно-исследовательский институт патологии, фармакологии и терапии Российской академии сельскохозяйственных наук

КАЛЮЖНЫЙ Иван Исаевич, Саратовский государственный аграрный университет имени Н.И. Вавилова

Исследования показали, что разработанный способ диагностики нарушений рубцового пищеварения ужвачнъх позволяет выявлять патологию на ранних этапах развития, а у больнъх животньх оценивать степень нарушения рубцового пищеварения и эффективность проводимого лечения. На клинически здоровое состояние животных указывает уровенъ содержания средних молекул (ССМ) в рубиовой жидкости, определяемый на волне 237 нм - менее 2,0 усл. ед., на волне 254 нм - менее 1,0 усл. ед., на волне 280 нм - менее 1,0 усл. ед.

Введение. Особенностью пищеварения жвачных животных является способность переваривать со сравнительно высокой эффективностью и в больших объемах клетчатку растительных кормов. Это возможно благодаря наличию у них многокамерного желудка и присущего им жвачного процесса. Наряду с превращением составных компонентов корма в соединения, доступные для усвоения животными, в рубце образуются витамины группы В и К в необходимом 
для организма количестве. Продукты расщепления растительных белков, небелковых азотсодержащих веществ рациона и поступающей из крови мочевины усваиваются в рубце бактериями и инфузориями. В результате образуется микробный белок, обеспечивающий 20-30\% потребности животных в протеине $[2,6,8]$. Нарушение рубцового пищеварения сопровождается снижением активности таких процессов, как деструктуризация компонентов рациона и наращивание микробиологической массы, что негативно отражается на эффективности кормления и уровне продуктивности животных.

Для выявления дисфункций рубца наиболее часто используются клинические методы исследования (осмотр, пальпация, аускультация, тонометрия и руменография) $[3,13,15]$ и лабораторные исследования рубцового содержимого, включающие в себя определение органолептических параметров, числа бактерий и инфузорий, концентрации аммиака, общего количества летучих жирных кислот, уксусной, пропионовой и масляной кислот, рН-метрию и др. [7].

Определяемые при этом показатели расширяют возможность выявления ранних стадий патологии, механизмов нарушения функций преджелудков и вторичных поражений других органов. Однако необходимость повышения информативности диагностических тестов и углубление знаний патогенеза нарушений рубцового пищеварения требуют разработки новых методов исследования. Основной причиной гибели бактерий, дрожжей и инфузорий являются неблагоприятные условия существования или наличие веществ, обладающих цитотоксическим действием. При этом если об изменении среды в рубце можно судить по уровню $\mathrm{pH}$, то тестов оценки токсичности рубцового содержимого в клинической практике нет. Поэтому целью исследования стала разработка нового метода оценки токсичности рубцового содержимого.

Методика исследований. Основой способа стал метод определения содержания в крови веществ со среднемолекулярной массой. Принцип метода заключается в осаждении высокомолекулярных (>5000 D) соединений раствором кислоты с последующим определением оптической плотности, показатели которой в определенных областях спектра пропорциональны содержанию фракций «средних» молекул [1]. Используя метод моделирования с помощью специальных рационов, воспроизвели наиболее распространенные варианты нарушения рубцового пищеварения у коров - ацидоз и алкалоз.

Объектом исследования были клинически здоровые коровы красно-пестрой и голштинской пород, из числа которых на 40-50-й день лактации были сформированы три группы. Все животные, задействованные в опыте, содержались на привязи в индивидуальных станках. Для каждой группы были разработаны рационы, идентичные по содержанию питательных веществ, витаминов и минералов, но отличающиеся уровнем протеина и углеводов. Животные из группы 1 (контроль, $n=100$ ) получали базовый рацион, соответствующий рекомендуемым нормам. Коровам группы $2(n=30)$ дополнительно к базовому рациону давали 4 кг свекловичной патоки, а группы $3(n=30)-250$ г мочевины (марка А). Приучение к высокой дозе мочевины осуществляли в течение 15 суток.

Клиническое обследование животных осуществляли общепринятыми методами. Отбор проб рубцового содержимого проводили с помощью рото-пищеводного зонда через 3 ч после очередного кормления. Полученные пробы рубцового содержимого исследовали в течение 2 ч после отбора. Пробу от каждого животного фильтровали через 4 слоя марли, после чего определяли $\mathrm{pH}$ электрометрическим методом и подсчитывали количество инфузорий в камере Горяева [7, 14]. Для определения молекул среднемолекулярной массы в пробирку вносили 1 мл рубцового содержимого и 0,5 мл рабочего раствора (10\%-й раствор трихлоруксусной кислоты), перемешивали стеклянной палочкой. Через 2 мин центрифугировали 15 мин при 3000 мин $^{-1}$. В чистую пробирку вносили 0,5 мл супернатанта и 4,5 мл дистиллированной воды, перемешивали и фотометрировали. Экстинкцию измеряли в диапазоне от 200 до 300 нм в кювете с толщиной слоя 1 см, раствор сравнения- 1 мл рабочего раствора и 29 мл дистиллированной воды).

Статистический анализ результатов проводили с использованием программы Statistica v 6.1, различия оценивали по критерию Стьюдента $(p<0,05)[5,9,10]$. Расчет референсного интервала ССМ в рубцовом содержимом у здоровых животных мы проводили с использованием программы Reference Value Advisor на базе Microsoft Excel, а оценку силы связи показателя ССМ в рубцовом содержимом с нарушением метаболического профиля в рубце осуществляли на основании показателя достоверности связи по критерию $\chi^{2}[4,8,11,12]$.

Результаты исследований. Результаты наблюдения за коровами контрольной группы показали, что их клиническое состояние в течение опыта существенно не изменялось. У животных группы 2 изменения клинического статуса были отмечены только на 25-й день опыта, когда у большинства (93,3 \%) из них отмечали снижение продуктивности на 8,7 \% (группа 1 19,4 кг, 2 - 17,7 кг) и содержания жира в молоке на $19,0 \%$ (35,9 и 29,1 г/л). Кроме того, у этих 
коров отмечали снижение аппетита, скрежет зубами и слезотечение. В группе 3 у отдельных животных (10\%) в течение первых 7 дней опыта наблюдались поносы и временное снижение аппетита, на 25-й день - снижение продуктивности на 5,1 \%, а у 16,7 \% (5 гол.) животных мышечная дрожь. У большинства коров имело место учащение пульса (110-160 уд./мин) и дыхания (28-34 дых. дв./мин).

В начале исследования у всех задействованных в опыте животных показатели рубцового пищеварения были в пределах нормы (табл. 1 ).

Животные из группы 1 были здоровы в течение всего опыта, а наблюдаемые изменения показателей рубцового содержимого и крови были обусловлены функциональной нагрузкой на организм коров в период раздоя.

У коров из группы 2 в сравнении с исходным уровнем не отмечено достоверных изменений руминации и показателей рубцового содержимого в течение первых 7 дней опыта. На 25-й день величина $\mathrm{pH}$ снизилась на 1,7 ед., в цвете содержимого усилились оттенки серого (молочного), а запах стал кислым. В сравнении с исходным уровнем возросла скорость седиментации на $90 \%$, снизилось количество простейших на $62,1 \%$, а число сокращений рубца в 4 раза.

У животных группы 3 достоверные изменения показателей рубцового содержимого были отмечены только на 25-й день опыта. В сравнении с исходным уровнем $\mathrm{pH}$ возросла на 0,9 ед., время седиментации уменьшилось в 2,8 раза, а количество инфузорий на 39 \%. Цвет содержимого стал более темный, а запах вначале аммиачный, затем появились гнилостные оттенки. Число жевательных движений во время пережевывания одной жвачки уменьшилось на 27,6 \%, а руминация ослабла в 2 раза.

Таким образом, используя метод моделирова- ния, были воспроизведены ацидоз рубца у коров из группы 2 и алкалоз рубца - из группы 3. Характерные для каждого метаболического профиля изменения моторики рубца и свойств его содержимого появлялись с 7-го по 25-й день действия неблагоприятных факторов кормления.

Используя базовый вариант метода определения ССМ на 25-й день опыта, провели оценку динамики ССМ в диапазоне от 200 до 300 нм; на основе среднеарифметических значений построили график (см. рисунок).

Анализ графиков показал высокую вариабельность показателей в интервале от 200 до $233,0 \pm 0,28$ нм. Так, коэффициент вариабельности С у здоровых животных составил 37,2 \%, у коров с ацидозом рубца - 29,5 \%, с алкалозом - 26,8 \%. У здоровых животных диаграмма формировала относительно стабильные отрезки от $233,7 \pm 0,32$ до $245,2 \pm 0,5$ нм $(\mathrm{C}=10,14 \%)$ и от $250,2 \pm 0,5$ до $285,0 \pm 0,025$ нм $(\mathrm{C}=8,07 \%)$. У больных с ацидозом и алкалозом имелся только один относительно стабильный отрезок $(\mathrm{C}=$ $=6,8 \%)$ в диапазоне от $234,9 \pm 0,45$ до $266,0 \pm$ $\pm 0,6 \mathrm{HM}$.

Таким образом, при исследовании рубцового содержимого наиболее приемлемы замеры ССМ в диапазонах 235-245 и 250-285 нм. Поэтому для сохранения возможности сравнения показателей в крови и рубцовом содержимом следует определять ССМ на длинах волн 237, 254 и 280 нм.

Расчет референсного интервала ССМ в рубцовом содержимом показал, что у здоровых животных ( $n=100)$ при определении ССМ на длине волны 237 нм он составил 0,5-2,0 усл. ед., на 254 нм - 0,31,0 усл. ед. и на 280 нм - 0,25-1,0 усл. ед.

Анализ полученных результатов методом Х-квадрат свидетельствует о том, что на ранних этапах развития ацидоза и алкалоза (7-й день

Таблица 1

Результаты рубцового пищеварения у коров

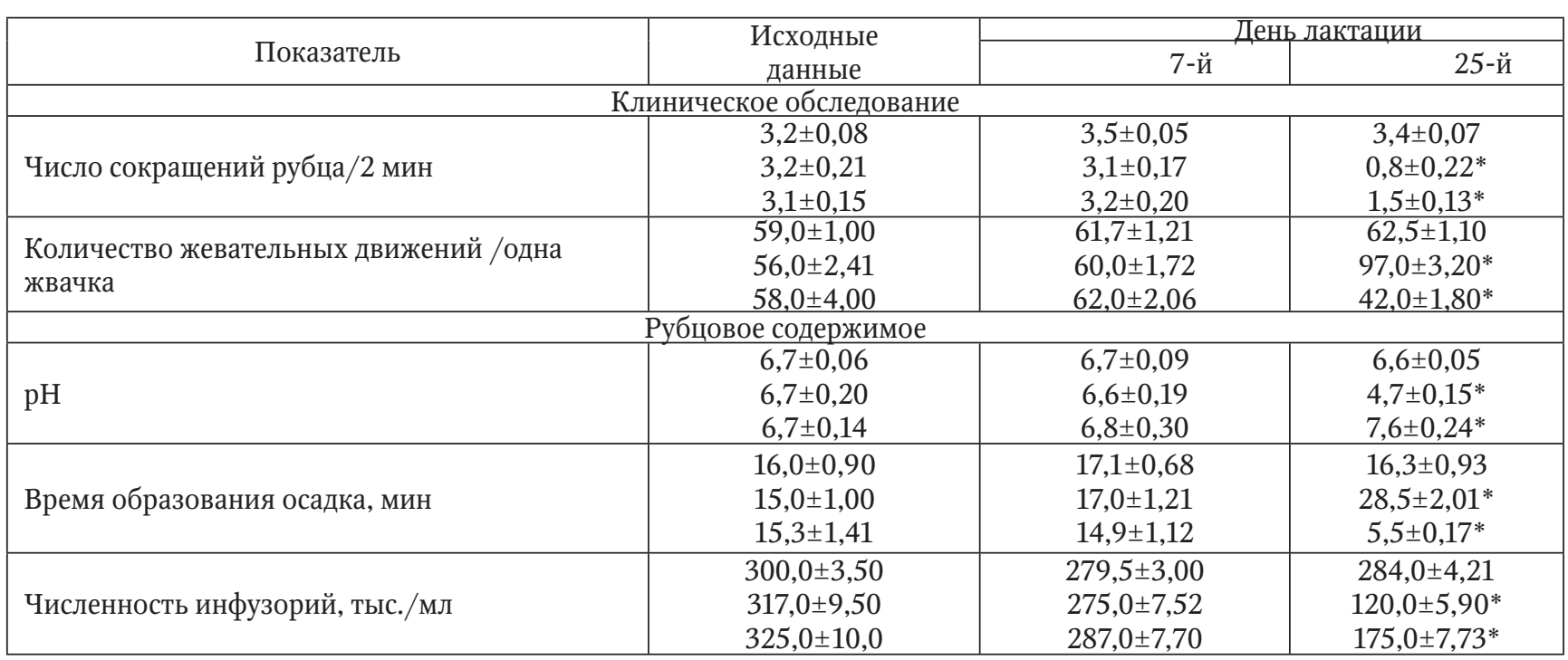




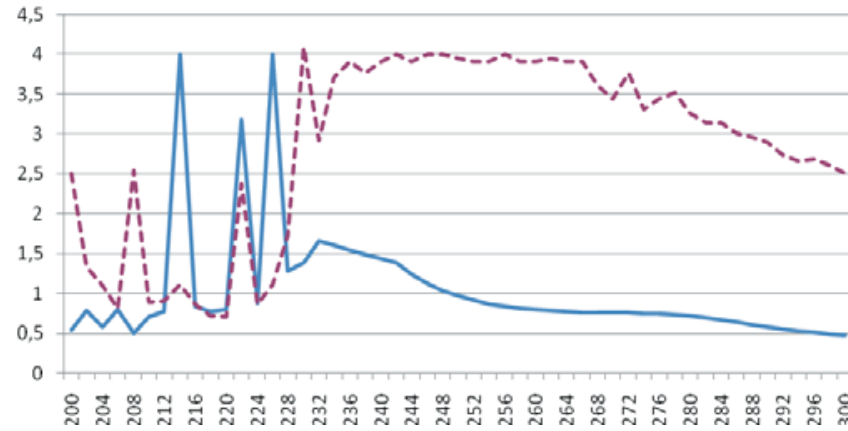

Динамика ССМ у зоровых (-) и больных (---) коров
при определении в диапазоне от 200 до 300 нм

Таблица 2

\section{Частота нарушений рубцового пищеварения у коров с разным уровнем ССМ в рубцовом содержимом $(n=160)$}

\begin{tabular}{|l|c|c|}
\hline \multirow{2}{*}{$\begin{array}{c}\text { ССМ, усл. ед. } \\
\text { (7-й день), на волне }\end{array}$} & \multicolumn{2}{|c|}{$\begin{array}{c}\text { Клиническое состояние } \\
\text { (25-й день опыта) }\end{array}$} \\
\cline { 2 - 3 } & здоровые, гол. & больные, гол. \\
\hline 237 нм: & 94 & 6 \\
$<2,0$ & 2 & 58 \\
$\geq 2,0$ & 88 & \\
\hline 254 нм: & 6 & 54 \\
$<1,0$ & & \\
$\geq 1,0$ & 82 & 18 \\
\hline 280 нм: & 9 & 51 \\
$<1,0$ & & \\
$\geq 1,0$ &
\end{tabular}

опыта), когда отсутствуют достоверные отклонения традиционных показателей рубцового содержимого, уже имеются достоверные отклонения ССМ (табл. 2). Так, показатель $\chi^{2}$ на длине волны 237 нм составил 124,8, а коэффициент детерминации $\left(r_{\mathrm{d}}\right)-0,77(P<0,001)$. При определении ССМ на 254 нм указанные параметры составили 90,0 и 0,49 , а на 280 нм - 65,7 и 0,4 $(P<0,001)$.

По данным табл. 2, между уровнем ССМ в рубцовом содержимом у жвачных животных и нарушениями метаболического профиля в рубце имеется сильная достоверная корреляционная связь при использовании длины волны 237 нм, а при 254 и 280 нм - средней степени выраженности. Доля влияния увеличения ССМ на длине волны 237 нм (выше 2,0 усл. ед.), 254 нм (выше 1,0 усл. ед.) и 280 нм (выше 1,0 усл. ед.) на нарушение рубцового пищеварения составляет соответственно 77, 49 и $40 \%$, что позволяет расценивать его как достоверный показатель ранней диагностики с высоким уровнем прогностического значения.

Заключение. Полученные результаты позволили сформировать оптимальный вариант метода определения ССМ в рубцовом содержимом.

Разработанный способ диагностики нарушений рубцового пищеварения у жвачных животных характеризуется сравнительно высокой прогностической и диагностической информа- тивностью. Его применение позволит выявлять патологию рубцового пищеварения на ранних стадиях ее развития. Это будет основанием для проведения корректировки рациона кормления или превентивной терапии, которая является более эффективной и экономически менее затратной. Кроме того, позволит оценивать тяжесть метаболических нарушений в рубце, что будет основанием для определения тактики лечения и оценки ее эффективности.

\section{СПИСОК ЛИТЕРАТУРЫ}

1. Алехин Ю.Н. Эндогенные интоксикации у животных и их диагностика. - Воронеж, 2000. - 12 с.

2. Белобороденко А.М, Белобороденко Т.А., Белобороденко М.А. Возрастная и сравнительная физиология пищеварения в многокамерном желудке у овец и крупного рогатого скота. - Тюмень: ГАУСЗ, 2015. - 140 с.

3. Гематологические параметры у коров при метаболических нарушениях в период беременности / И.И. Калюжный [и др.] // Актуальные проблемы ветеринарной медицины, пищевых и биотехнологий: материалы Междунар. науч.-практ. конф. - Саратов: Наука, 2016. - 581 с.

4. Гржибовский А.М., Иванов С.В., Горбатова М.А. Корреляционный анализ данных с использованием программного обеспечения STATISTICA и SPSS // Наука и здравоохранение. - 2016. - № 1. - С. 7-36.

5. Гржибовский А.М., Иванов С.В., Горбатова М.А. Описательная статистика с использованием пакетов статистических программ STATISTICA и SPSS // Наука и здравоохранение. - 2017. - №1. - С. 7-23.

6. Калмычина Е.В., Калюжный И.И., Степанов И.С. Значение микрофлоры рубца в пищеварении // Актуальные проблемы ветеринарной медицины, пищевых и биотехнологий: материалы Междунар. науч.-практ. конф. - Саратов, 2017. - С. 240-243.

7. Калюжный И.И., Гречишкин А.С. Показатели кислотно-основного состояния при ацидозе у высокопродуктивных молочных коров // Современные способы повышения продуктивных качеств с.-х. животных, птицы и рыбы в свете импортозамещения и обеспечения продовольственной безопасности: материалы науч.-практ. конф., посвящ. 85-летию со дня рождения д-ра с.-х. наук, проф. А.П. Коробова. - Саратов: Науч. книга, 2015. - 404 с.

8. Клиническая гастроэнтерология животных: учеб. пособие / под ред. И.И. Калюжного. - 2-е изд., испр. - СПб.: Лань, 2015. - 448 с.

9. Консервирование влажного плющеного зерна кукурузы новым биологическим консервантом / М.Д.Каширская[идр.]//Кормопроизводство.-2017.№ 12. - С. 34-38.

10. Методы ветеринарной клинической лабораторной диагностики: справочник / под ред. проф. И.П. Кондрахина. - М.: КолосС, 2004. - 520 с.

11. Нарушение метаболических процессов в организме беременных коров при развитии субклинического кетоза / С.Н. Бабухин [и др.] // Аграрный научный журнал. - 2016. - № 11. - С. 6-11.

12. Системные метаболические нарушения в организме сухостойных коров / С.Н. Бабухин [и др.] // Актуальные проблемы ветеринарной медицины, пищевых и биотехнологий: материалы Междунар. науч.- 
практ. конф. - Саратов, 2017. - С 14-17.

13. Уша Б.В. Клиническая диагностика внутренних незаразных болезней. - СПб.: Квадро, 2013. - 490 с.

14. Физиология сельскохозяйственных животных / В.Г. Гусаков [и др.]. -Витебск, 2008. - 274 с.

15. Reference Value Advisor: a new freeware set of macroinstructions to calculate reference intervals with Microsoft Excel / A. Geffre [et al.] // Vet. Clin. Pathol., 2011, Vol. 40, No. 1, P. 107-112.

Алехин Юрий Николаевич, $\partial-p$ вет. наук, главный научный сотрудник, Всероссийский научно-исследовательский институт патологии, фармакологии и терапии Российской академии сельскохозяйственных наук. Россия.

Жуков Максим Сергеевич, канд. вет. наук, младший научный сотрудник, Всероссийский научно-исследовательский институт патологии, фармакологии и терапии Российской академии сельскохозяйственных наук. Россия.

394087, г. Воронеж, ул. Ломоносова, 114-Б.

Тел.: (473) 253-62-10.

Калюжный Иван Исаевич, $\partial-p$ вет. наук, проф. кафедры «Болезни животных и ветеринарно-санитарная экспертиза», Саратовский государственный аграрный университет имени Н.И. Вавилова.

410012, г. Саратов, Театральнаяпл., 1.

Тел.: (8452) 69-24-25.

Ключевые слова: крупный рогатый скот; рубцовое пищеварение; метод диагностики; эндогенная интоксикация; ацицоз; алкалоз.

\title{
UNIFICATION OF THE METHOD FOR DETERMINING THE AVERAGE MASS MOLECULES FOR THE DIAGNOSIS OF DISORDERS OF CICATRI-CAL DIGESTION IN RUMINANTS
}

Alekhin Yurij Nikolaevich, Doctor of Veterinary Sciences, State Scientific Institu-tion All-Russian Veterinary Research Institute of Pathology, Pharmacology and Therapy of the Russian Academy of Agricultural Sciences. Russia.

Zhukov Maksim Sergeevich, Junior Researcher, State Scientific Institution All-Russian Veterinary Research Institute of Pathology, Pharmacology and Therapy of the Russian Academy of Agricultural Sciences. Russia.

Kalyuzniy Ivan Isaevich, Doctor of Veterinary Sciences, Professor of the chair "Diseases of Animals and Veterinarian-sanitarian Expertise", Saratov State Agrar-ian University named after N.I. Vavilov. Russia.
Keywords: cattle; cicatricial digestion; method of diagnosis; endogenous intoxica-tion; acidosis; alkalosis.

Abstract. The carried out researches have shown that the developed way of diag-nostics of disorders of cicatrical digestion in ruminants allows to reveal a pathol-ogy at early stages of development, and in patients - to estimate the degree of vio-lation of cicatricial digestion and the effectiveness of the treatment. The clinically healthy state of animals is indicated by the level of the content of the average molecules (CAM) in the scar liquid, determined at a wavelength of $237 \mathrm{~nm}$ - less than 2.0 conventional units, at a wave of $254 \mathrm{~nm}$ - less than 1.0 conventional units, at a wavelength of $280 \mathrm{~nm}$ - less than 1.0 conventional units.

удк 619612.1.636.2

\section{ВЛИЯНИЕ НЕОРГАНИЧЕСКИХ И ОРГАНИЧЕСКИХ ФОРМ МИКРОЭЛЕМЕНТОВ НА МЕТАБОЛИЧЕСКИЕ ПРОЦЕССЫ В ОРГАНИЗМЕ ДОЙНЫХ КОРОВ}

\author{
БЫКОВА Елена Владимировна, Саратовский государственный аграрный университет имени \\ Н.И. Вавилова
}

КОРОБОВ Александр Петрович, Саратовский государственный аграрный университет имени Н.И. Вавилова

КАЛЮЖНЫЙ Иван Исаевич, Саратовский государственный аграрный университет имени Н.И. Вавилова

ГУМЕНЮК Анатолий Петрович, $A O$ «Биоамид»

Изучено влияние неорганическх и органических форм микроэлементов на метаболические процессы в организме дойных коров. Установлено, что различные формы микроэлементов действуют на обменные процессы в организме животных. Лучшие показатели, в пределах физиологических норм, морфологического и биохимического состава крови были у животных, получавших в составе премиксов органические соединения марганца, иинка, меди, кобальта, селена и йода. Введение в состав рационов коров органических форм микроэлементов улучшает молочную продуктивность и качественные показатели молока.

Введение. Недостаток минеральных веществ в рационах животных традиционно принято компенсировать введением их в корма в неорганической форме в виде сульфатов, карбонатов, хлоридов и др. В последние годы во всем мире проявляется интерес к использованию органических соединений микроэлементов [7]. Российской компанией АO «Биоамид» разработан новый органический продукт - «Органические микроэлементные комплексы на основе органических соединений («ОМЭК-7МЭ»)».
Особенность «ОМЭК-7МЭ» состоит в том, что он представляет собой готовую смесь необходимых микроэлементов в форме органических соединений с оптимальным соотношением составных частей для любого вида животных. Микроэлементная часть, включающая металлы (железо, медь, цинк, марганец, кобальт), представляет собой комплексные соединения их c L-аспарагиновой кислотой. Смесь соединений металлов с L-аспарагиновой кислотой получают из единого технологического раствора и любые высушенные частицы смеси аб- 